\title{
Structural diversity in hybrid Vanadium (IV) Oxyfluorides based on a Common Building Block
}

\author{
Farida H. Aidoudi ${ }^{a}$, Cameron Black ${ }^{a}$, Kasun S. Athukorala Arachchige ${ }^{a}$, Alexandra M. Z. Slawin ${ }^{a}$, \\ ${ }_{5}$ Russell E. Morris $^{\mathrm{a}}$ and Philip Lightfoot ${ }^{\mathrm{a}}$ \\ Received (in $X X X, X X X) X$ th $X X X X X X X X X 20 X X$, Accepted Xth $X X X X X X X X X 20 X X$ \\ DOI: $10.1039 / b 000000 x$
}

There are only limited reports on vanadium (IV) oxyfluorides (VOFs) with extended crystal structures. Here we expand and enrich the list of existing VOFs with a series of 14 new materials "VOF-n ( $n=1$ -

10 14)" prepared using ionothermal and solvothermal synthesis methods. All these materials arise from the condensation of a dimeric structural motif. These VOFs can be classified into three groups depending on their key structural features; layer structures: VOF-1 " $\left[\mathrm{HN}_{2} \mathrm{C}_{7} \mathrm{H}_{6}\right]\left[\mathrm{V}_{2} \mathrm{O}_{2} \mathrm{~F}_{5}\right]$ ", VOF-2

" $\left[\mathrm{HN}_{2} \mathrm{C}_{4} \mathrm{H}_{4}\right]\left[\mathrm{V}_{2} \mathrm{O}_{2} \mathrm{~F}_{5}\right]$ ", VOF-3 " $\left[\mathrm{HN}_{2} \mathrm{C}_{3} \mathrm{H}_{4}\right]\left[\mathrm{V}_{2} \mathrm{O}_{2} \mathrm{~F}_{5}\right]$ and VOF-4 " $\mathrm{V}_{2}\left(\mathrm{~N}_{2} \mathrm{C}_{4} \mathrm{H}_{4}\right) \mathrm{O}_{2} \mathrm{~F}_{4}$ ", ladder like

structures: VOF-5 " $\left[\mathrm{NH}_{4}\left(\mathrm{HN}_{2} \mathrm{C}_{3} \mathrm{H}_{4}\right)\right]\left[\mathrm{V}_{2} \mathrm{O}_{2} \mathrm{~F}_{6}\right]$ ”, VOF-6 " $\left[\mathrm{K}\left(\mathrm{HN}_{2} \mathrm{C}_{3} \mathrm{H}_{4}\right)\right]\left[\mathrm{V}_{2} \mathrm{O}_{2} \mathrm{~F}_{6}\right]$ ”, VOF-7

15 " $\left[\mathrm{HNH}_{2} \mathrm{CH}_{2} \mathrm{CH}_{3}\right]\left[\mathrm{VOF}_{3}\right]$ ", VOF-8 " $\left[\mathrm{HN}_{2} \mathrm{C}_{7} \mathrm{H}_{6}\right]\left[\mathrm{VOF}_{3}\right]$ ", VOF-9 " $\left[\mathrm{H}_{2} \mathrm{~N}_{2} \mathrm{C}_{4} \mathrm{H}_{6}\right]\left[\mathrm{V}_{2} \mathrm{O}_{2} \mathrm{~F}_{6}\right]$ ”, VOF-10 " $\beta$ -

$\mathrm{RbVOF}_{3}$ ”, VOF-11 “ $\alpha-\mathrm{KVOF}_{3}$ ”, VOF-12 " $\beta-\mathrm{KVOF}_{3}$ ”, VOF-13 “ $\left[\mathrm{H}_{2}\left(\mathrm{NH}_{2}\right)_{2}\left(\mathrm{CH}_{2}\right)_{2}\right]\left[\mathrm{V}_{2} \mathrm{O}_{2} \mathrm{~F}_{6}\right]$, and a

chain structure: VOF-14 " $\left[\mathrm{H}_{2} \mathrm{~N}_{2} \mathrm{C}_{6} \mathrm{H}_{12}\right]\left[\mathrm{V}_{2} \mathrm{O}_{2} \mathrm{~F}_{7}\right]$ ". The crystal structures of VOF-n are presented, and

their synthetic and structural relationships are discussed.

\section{${ }_{20}$ Introduction}

Compounds of vanadium (IV) exhibiting extended lattice structures are of interest for a variety of properties and applications, for example as lithium battery cathodes, ${ }^{1}$ frustrated magnets ${ }^{2}$ and oxidation catalysts. ${ }^{3}$ We have focused our own 25 interest over the past few years on the synthesis of metal (oxy)fluorides ${ }^{4}$ with particular emphasis on developing novel hybrid organic-inorganic vanadium (oxy)fluorides using various synthetic methods, including hydrothermal and ionothermal systems. This has resulted in a wide range of materials containing 30 vanadium in III, IV or V oxidation states. $\frac{5-8}{5}$

The many variables involved in both hydrothermal and ionothermal systems illustrate their complexity, and in the course of our exploratory studies we have found that the outcomes of these reactions are very sensitive to small changes in conditions.

35 In addition to the vital role of the solvent, many other factors $(e . g$. vanadium source, amount of HF, nature and amount of the added template and others) may affect the reaction outcome. Although the direct impact of these parameters on the resulting materials is not yet fully understood, there is a clear indication of the 40 propensity of ionothermal systems ${ }^{9}$, i.e. using ionic liquids (ILs) as the reaction solvent, to produce more extended V(IV)containing fluorides. For instance hydrothermal synthesis mainly produces low dimensional VOFs; monomeric, oligomeric or chain-type structures are all accessible hydrothermally at low
45 reaction temperatures. On the other hand more extended VOF structures are accessible using ionothermal synthesis, where a hydrophobic IL, 1-ethyl-3-methylimidazolium bis (trifluoromethylsulfonyl)imide $\left(\mathrm{EMIM} \mathrm{Tf}_{2} \mathrm{~N}\right)$ is used as the reaction solvent. Initially, this led to the preparation of the first ${ }_{50} \mathrm{VOF}$ with a 2-D connectivity, $[\mathrm{H} p y r]\left[\mathrm{V}_{2} \mathrm{O}_{2} \mathrm{~F}_{5}\right], \underline{10}$ and subsequently, a similar approach allowed us to prepare a VOF with a pillared-layer kagome lattice,

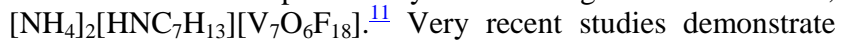
that this material displays unusual gapless quantum spin-liquid 55 behaviour. $\underline{12}$

We have pursued further research on both ionothermal and hydrothermal synthesis of VOFs, yielding a variety of further, novel V(IV)-containing materials with a very rich crystal chemistry. All the materials reported herein contain vanadium in 60 the IV oxidation state, and are based on a common dimeric structural motif. The order in which the structures are presented follows their dimensionality, and the structures are given the symbols VOF-n

\section{Experimental Section}

65

\section{Synthesis}

All reagents were commercially available and used without further purification, except the ionic liquids EMIM $\mathrm{Tf}_{2} \mathrm{~N}$ and $\mathrm{N}$ butylpyridinium bromide (BPB), which were synthesised 70 according to the literature procedure.., 14 


\section{Cite this: DOI: $10.1039 / \mathrm{c0xx} 00000 \mathrm{x}$}

\section{www.rsc.org/xxxxxx}

PAPER

Table 1 Crystallographic Data for VOF-3, VOF-4, VOF-13 and VOF-14

\begin{tabular}{|c|c|c|c|c|}
\hline & VOF-3 & VOF-4 & VOF-13 & VOF-14 \\
\hline Formula & {$\left[\mathrm{HC}_{3} \mathrm{~N}_{2} \mathrm{H}_{4}\right]\left[\mathrm{V}_{2} \mathrm{O}_{2} \mathrm{~F}_{5}\right]$} & $\mathrm{V}_{2}\left(\mathrm{~N}_{2} \mathrm{C}_{4} \mathrm{H}_{4}\right) \mathrm{O}_{2} \mathrm{~F}_{4}$ & {$\left[\mathrm{H}_{2}\left(\mathrm{NH}_{2}\right)_{2}\left(\mathrm{CH}_{2}\right)_{2}\right]\left[\mathrm{V}_{2} \mathrm{O}_{2} \mathrm{~F}_{6}\right]$} & {$\left[\mathrm{H}_{2} \mathrm{~N}_{2} \mathrm{C}_{6} \mathrm{H}_{12}\right]\left[\mathrm{V}_{2} \mathrm{O}_{2} \mathrm{~F}_{7}\right]$} \\
\hline $\mathrm{Fw} / \mathrm{g} / \mathrm{mol}$ & 297.97 & 289.97 & 310 & 381.07 \\
\hline Space group & $P 2_{1}(4)$ & $P 2{ }_{1} / c(14)$ & $P 2_{1} / m(11)$ & $C 2 / c(15)$ \\
\hline$a / A ́$ & $7.170(3)$ & $5.0096(14)$ & $8.806(3)$ & $10.0330(19)$ \\
\hline$b / A$ & $17.333(7)$ & $10.8260(3)$ & $12.100(5)$ & $10.0380(17)$ \\
\hline$c / \not{A}$ & $7.370(4)$ & $7.288(7)$ & $9.206(4)$ & $11.930(2)$ \\
\hline$\alpha /{ }^{\circ}$ & 90 & 90 & 90 & 90 \\
\hline$\beta /{ }^{\circ}$ & $118.0531(10)$ & $95.9430(10)$ & $106.301(2)$ & $110.170(3)$ \\
\hline$\gamma / 0$ & 90 & 90 & 90 & 90 \\
\hline$V / A^{3}$ & $808.32(6)$ & 393.1(4) & $941.49(6)$ & $1127.8(3)$ \\
\hline $\mathrm{Z}$ & 4 & 2 & 4 & 4 \\
\hline Crystal size $/ \mathrm{mm}$ & $0.25 \times 0.03 \times 0.02$ & $0.20 \times 0.20 \times 0.12$ & $0.2 \times 0.2 \times 0.2$ & $0.05 \times 0.05 \times 0.05$ \\
\hline Crystal shape and colour & Blue needle & Blue platelet & Blue prism & Blue prism \\
\hline $\mathrm{F}(000)$ & 576 & 280 & 608 & 680 \\
\hline $\mathrm{R}_{\text {int }}$ & 0.0509 & 0.0247 & 0.0601 & 0.1031 \\
\hline Obsd data $[I>2 \sigma(I)]$ & 1875 & 612 & 1711 & 891 \\
\hline Data/restraints/parameters & $2153 / 1 / 254$ & $710 / 0 / 72$ & $1821 / 0 / 125$ & $1046 / 0 / 96$ \\
\hline GOOF on $\mathrm{F}^{2}$ & 1.013 & 1.069 & 1.241 & 1.019 \\
\hline $\mathrm{R} 1, w \mathrm{R} 2(\mathrm{I}>2 \sigma(\mathrm{I}))$ & $0.0395,0.0772$ & $0.0262,0.0540$ & $0.1123,0.2515$ & $0.0871,0.2332$ \\
\hline $\mathrm{R} 1, w \mathrm{R} 2$ (all data) & $0.0468,0.0815$ & $0 . .0337,0.0565$ & $0.1180,0.2551$ & $0.0970,0.2486$ \\
\hline Largest diff. peak / hole & $0.522 /-0.504$ & $0.318 /-0.368$ & $2.314 /-1.787$ & $1.775 /-0 . .847$ \\
\hline
\end{tabular}

Among the VOFs presented here, only VOF-10, VOF-11 and ${ }_{5}$ VOF-12 were synthesised solvothermally in a $40 \mathrm{~mL}$ Teflonlined stainless steel autoclave using either a mixture of water/DMSO or water/ethylene glycol. All the other VOFs were made ionothermally in a $30 \mathrm{~mL}$ Teflon-lined stainless steel autoclave.

10

All the ionothermally prepared VOFs were synthesised following a typical synthesis procedure: a Teflon-lined autoclave (volume $30 \mathrm{~mL})$ was charged with $\mathrm{VOF}_{3}(0.124 \mathrm{~g}, 1 \mathrm{mmol}$, Sigma Aldrich) (or $\mathrm{V}_{2} \mathrm{O}_{5}(0.182 \mathrm{~g}, 1 \mathrm{mmol}$, Sigma Aldrich) in the case 15 of VOF-13) and $\mathrm{HF}\left(48 \mathrm{wt} \%\right.$ in $\left.\mathrm{H}_{2} \mathrm{O}\right)(0.1 \mathrm{~mL}, 2.76 \mathrm{mmol}$, Sigma Aldrich) or $1 \mathrm{~mL}, 27.6 \mathrm{mmol}$, Sigma Aldrich in the case of VOF-13) and then the IL EMIM Tf ${ }_{2} \mathrm{~N}(4 \mathrm{~g}, \sim 10 \mathrm{mmol}$ ) (or the IL EPB $2.16 \mathrm{~g}, \sim 10 \mathrm{mmol}$ in the case of VOF-13) was added along with the added template; benzimidazole (VOF-1 and VOF-8), 20 pyrazine (VOF-2 and VOF-4), imidazole (VOF-3 and VOF-5), imidazole and $\mathrm{KNO}_{3}$ (VOF-6), ethylamine (VOF-7), 2methylimidazole (VOF-9), ethylenediamine (VOF-13) and 1,4diazabicyclo[2.2.2] octane (DABCO) (VOF-14).

For VOF-1, VOF-2, VOF-3, VOF-5, VOF-6, VOF-7, VOF-8 25 and VOF-9 the stainless steel autoclave was then sealed and heated in an oven at $170^{\circ} \mathrm{C}$ for $24 \mathrm{hrs}$; for VOF-4 and VOF-13 the autoclave was heated at $140^{\circ} \mathrm{C}$ for $24 \mathrm{hrs}$ and for VOF-14 the autoclave was heated at $130^{\circ} \mathrm{C}$ for $24 \mathrm{hrs}$. After the autoclave had been cooled to room temperature, the product was filtered, 30 washed with methanol and dried in air for $24 \mathrm{hrs}$.

A general scheme for the synthesis of VOF-10, VOF-11 and VOF-12 solvothermally is as follows: a Teflon-lined autoclave (volume $40 \mathrm{~mL})$ was charged with $\mathrm{V}_{2} \mathrm{O}_{5}((0.182 \mathrm{~g}, 1 \mathrm{mmol}$,
Sigma Aldrich) and $\mathrm{RbF}(0.209 \mathrm{~g}, 2 \mathrm{mmol})$ or $\mathrm{K}_{2} \mathrm{CO}_{3}(0.136 \mathrm{~g}, 1$ $35 \mathrm{mmol})$ and $\mathrm{HF}\left(48 \mathrm{wt} \%\right.$ in $\left.\mathrm{H}_{2} \mathrm{O}\right)(0.5 \mathrm{~mL}, 13.8 \mathrm{mmol}$, Sigma Aldrich). and then a solution of 3:1 $\mathrm{H}_{2} \mathrm{O} / \mathrm{DMSO}, 4: 5$ $\mathrm{H}_{2} \mathrm{O}$ /ethylene glycol or 7:1 $\mathrm{H}_{2} \mathrm{O} /$ ethylene glycol was added respectively. The stainless steel autoclave was then sealed and heated in an oven at $160^{\circ} \mathrm{C}$ for $24 \mathrm{hrs}$ or $72 \mathrm{hrs}$.

${ }_{40}$ The synthesis procedure for the ILs and for each compound can be found in full detail in the supplementary material.

\section{X-ray Crystallography.}

${ }_{45}$ Single crystal X-ray diffraction data for VOF-1 were collected at station 11.3.1 of the Advanced Light Source at Lawrence Berkeley National Laboratories, California using a Bruker APEX II CCD diffractometer. Single crystal X-ray diffraction data for

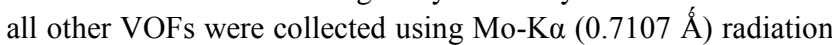
50 utilising a Rigaku rotating anode single-crystal X-ray diffractometer at the University of St Andrews. The structures were solved with standard direct methods using SHELXS and refined with least-squares minimisation techniques against $\mathrm{F}^{2}$ using SHELXL within the WinGX packages.

${ }_{55}$ Powder XRD was carried out on a Stoe STADI/P diffractometer using $\mathrm{Cu} \mathrm{K}_{\alpha 1} \mathrm{X}$-rays

VOF-3 displays an inorganic layer that shows an interesting variation to the one previously seen in $[\mathrm{Hpyr}]\left[\mathrm{V}_{2} \mathrm{O}_{2} \mathrm{~F}_{5}\right] . \stackrel{10}{=}$ VOF-4, 


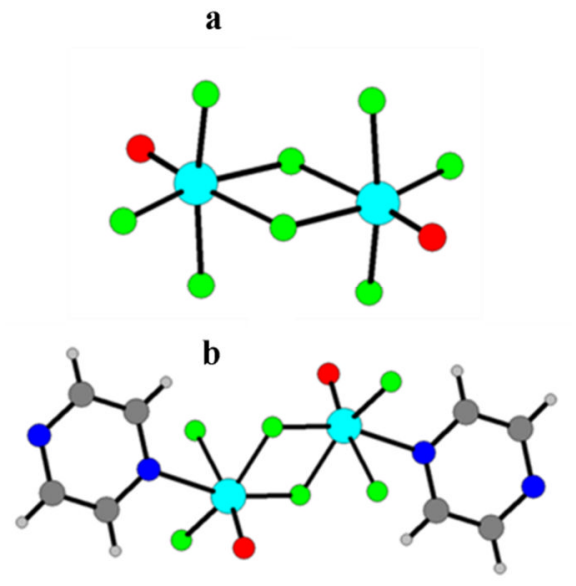

Fig.1 The dimeric $\left[\mathrm{V}_{2} \mathrm{O}_{2} \mathrm{~F}_{8}\right]^{4-}$ building units observed in (a) all the VOF-n structures except VOF-4 and (b) dimeric unit observed in VOF-4

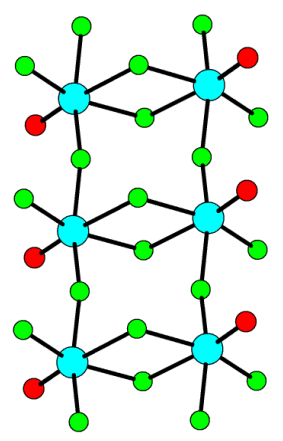

Fig.2 Ladder type $\left[\mathrm{VOF}_{3}\right]_{\mathrm{n}}{ }^{\mathrm{n}-}$ chain

VOF-13 and VOF-14 display novel polyhedral connectivities that are unprecedented in this class of materials. For space reasons only the crystallographic details for these materials are presented in Table.1; for all the other structures they are tabulated 10 in the supplementary material.

\section{Magnetic Measurements.}

Magnetic susceptibility data for VOF-13 were collected on a ${ }_{15}$ Quantum Design MPMS SQUID. Data were recorded in a 2000 Oe field while warming the sample from 1.8 to $300 \mathrm{~K}$ in $4 \mathrm{~K}$ steps, following consecutive zero-field cooling (ZFC) and field cooling (FC) cycles. Data were normalized to the molar quantity of the sample, and corrected for any diamagnetic contributions.

20

\section{Results and Discussion}

\section{Crystal structures}

${ }_{25}$ The VOF structures presented here fall into three major groups: 2-D layers, 1-D ladder-like chains and a 1-D single chain.

Interestingly all these structures can be regarded as arising from the same structural motif, where in all the structures the coordination environment around each vanadium atom is highly 30 distorted (typical characteristic of $\mathrm{V}(\mathrm{IV})$ in vanadium oxyfluorides) due to the presence of the short vandyl $\mathrm{V}=\mathrm{O}$ bond $(\sim 1.6 \AA \AA)$ and the corresponding elongated trans $\mathrm{V}-\mathrm{F}$ bond $(\sim 2.2$

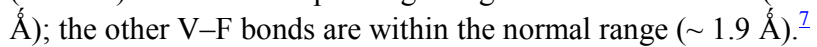

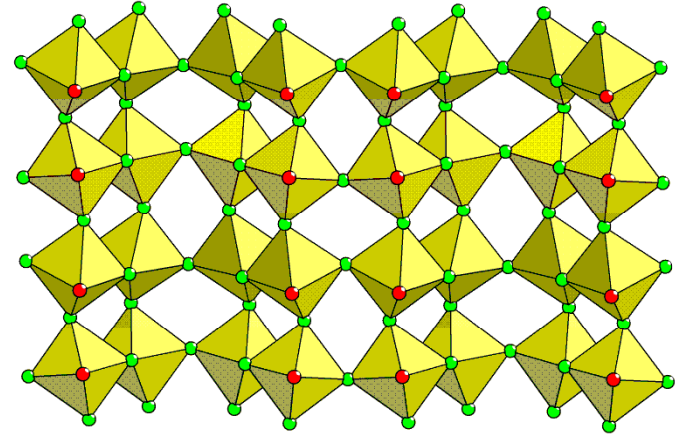

Fig.3 $\left[\mathrm{V}_{2} \mathrm{O}_{2} \mathrm{~F}_{5}\right]_{\mathrm{n}}{ }^{\mathrm{n}-}$ layer found in VOF-1 and VOF-2

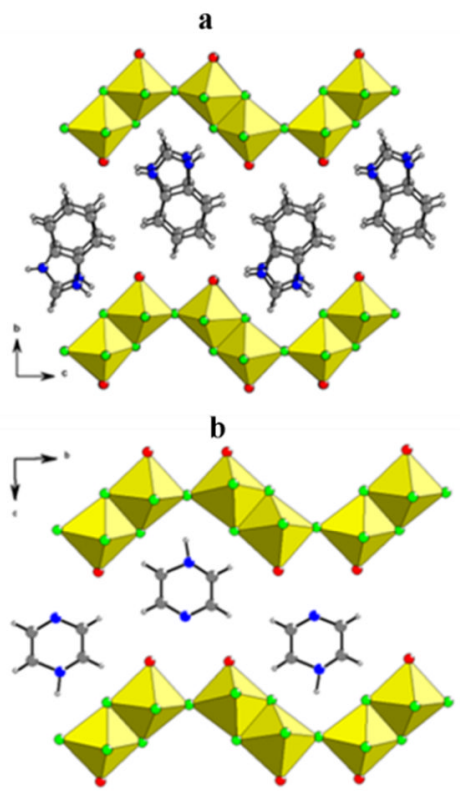

Fig.4 A view of the layer packing in (a) VOF-1 and (b) VOF-2

The vanadyl group is terminal in all the structures, with an 40 additional common feature being two $\mathrm{F}$ atoms bridging two adjacent octahedral units into an edge-shared dimer. These dimers, are then further linked to others in different ways to form layers, ladders or chains. The dimer in VOF-4 is slightly different with the vanadyl group being cis- rather than trans- to the 45 bridging $\mathrm{F}$ atoms, and two $\mathrm{N}$ atoms from the pyrazine ligand taking up one of the trans- positions (V-N distance 2.121(3) $\AA$ ). These two types of edge-shared-dimers are shown in Fig.1.

VOF-1 and VOF-2 arise from the condensation of the edge50 shared dimers, described earlier, through bridging $\mathrm{F}$-atoms to form infinite "ladder" like chains (Fig.2). These chains are further linked through $\mathrm{F}$ atoms leaving only $\mathrm{O}$ atoms terminal, to form an infinite anionic layer of composition $\left[\mathrm{V}_{2} \mathrm{O}_{2} \mathrm{~F}_{5}\right]_{n}{ }^{\mathrm{n}-}$ (Fig.3), similar to the one previously seen in $[\mathrm{Hpyr}]\left[\mathrm{V}_{2} \mathrm{O}_{2} \mathrm{~F}_{5}\right] .{ }^{10}$ These layers are 55 separated via hydrogen-bonded protonated organic amine moieties, benzimidazolium, or pyrazinium (Fig. 4)

In VOF-1 there are four vanadium ions in the asymmetric unit, and in VOF-2 there are two vanadium ions in the asymmetric unit, all of which are in the 4+ oxidation state as confirmed by ${ }_{60}$ bond valence sum calculations (see supplementary 


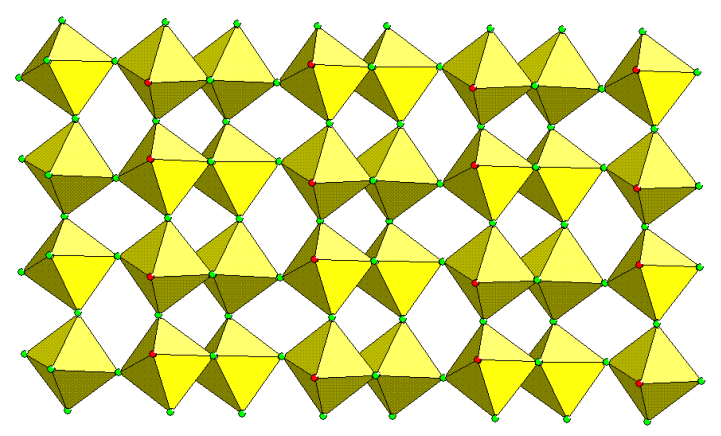

Fig.5 $\left[\mathrm{V}_{2} \mathrm{O}_{2} \mathrm{~F}_{5}\right]_{\mathrm{n}}{ }^{\mathrm{n}-}$ layer found in VOF-3

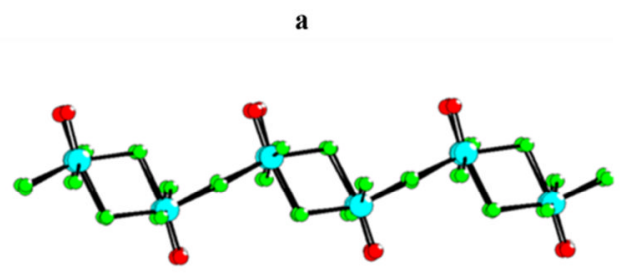

b

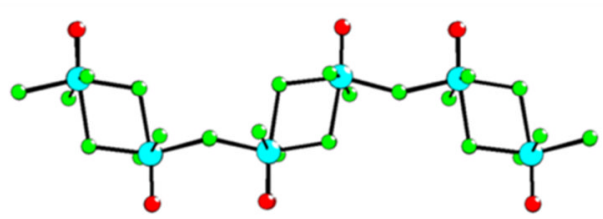

${ }_{5}$ Fig.6 A view of the polymorphic $3\left[\mathrm{~V}_{2} \mathrm{O}_{2} \mathrm{~F}_{5}\right]_{\mathrm{n}}^{\mathrm{n}-}$ layers: (a) found in VOF3 (b) found in VOF-1 and VOF-2

material).

${ }_{10}$ VOF-3 is also constructed from the edge-shared dimer described earlier, with the dimers sharing $\mathrm{F}$ atoms to form infinite "ladder" like chains in a similar way as VOF-1 and VOF-2. These chains are then joined through $\mathrm{F}$ atoms to form an infinite anionic layer (Fig. 5). Interestingly, as shown in Fig.6, the ladders in VOF-3 15 are linked in a different way compared to VOF-1 and VOF-2. In VOF-3 the nearest "vanadyl" bonds from two adjacent ladders point in opposite directions (Fig.6(a)); in contrast, in VOF-1 and VOF-2 they point in the same direction (Fig.6(b)).

In VOF-3 the layers are separated via hydrogen-bonded 20 protonated imidazolium cations (Fig.7).

It can be seen that the arrangement of the ladders within two different layers in VOF-1 and VOF-2 follow the same pattern previously seen in $[\mathrm{Hpyr}]\left[\mathrm{V}_{2} \mathrm{O}_{2} \mathrm{~F}_{5}\right]$ : ie. corrugated layers arranged

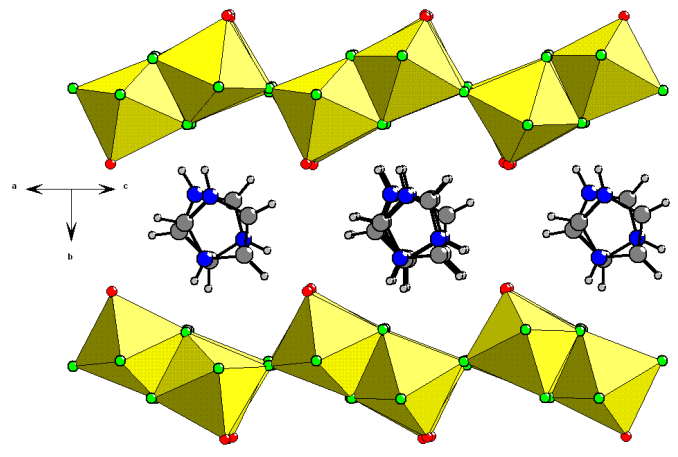

Fig.7 A view of the layer packing in VOF-3

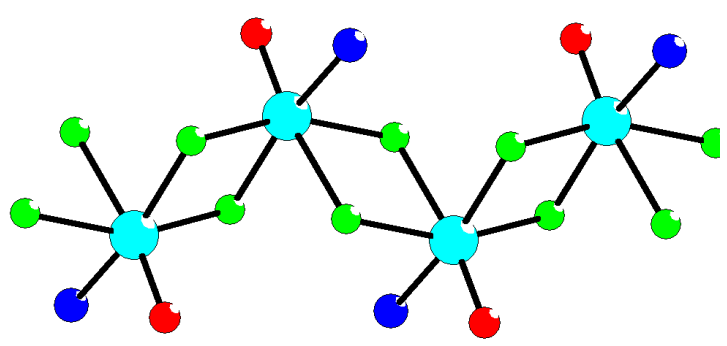

Fig.8 Inorganic chain found in VOF-4

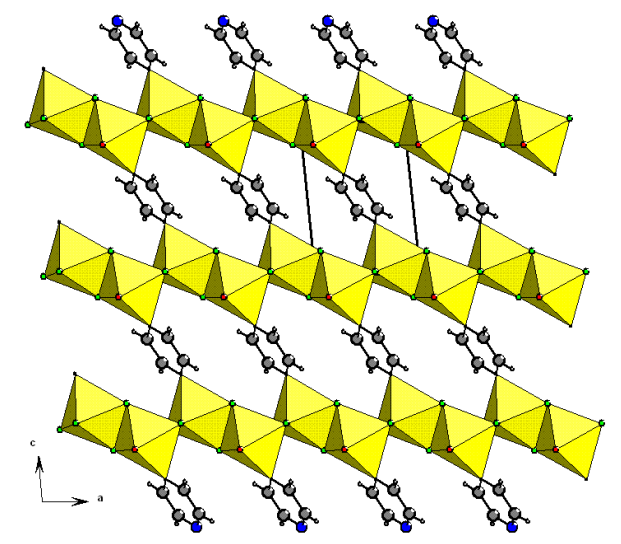

Fig.9 The V(IV) oxyfluoride/pyrazine layer found in VOF-4

parallel to each other while in VOF-3 they are quite different, and are aligned in nearly anti-parallel fashion.

35

VOF-4 displays a 2-D coordination polymer motif, built up from the edge-sharing dimer described earlier (Fig.1(b)), which is further linked to other adjacent dimers through two bridging Fatoms to form an edge-sharing "zigzag" chain (Fig.8). These 40 chains are bridged by the pyrazine ligand to form infinite metalorganic sheets (Fig.9 and Fig.10).

In VOF-4 there is only one single vanadium ion in the $4+$ oxidation state as confirmed by bond valence sum calculations $45\left(\sum \mathrm{V} 1=3.77\right)$.

Edge-sharing octahedral chains bridged by organic ligands have 

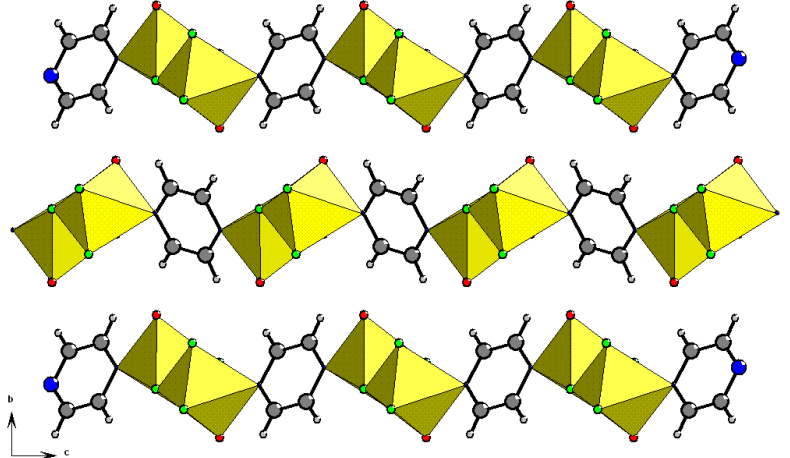

Fig.10 Structure of VOF-4 viewed along the $a$ axis, showing stacks of layers

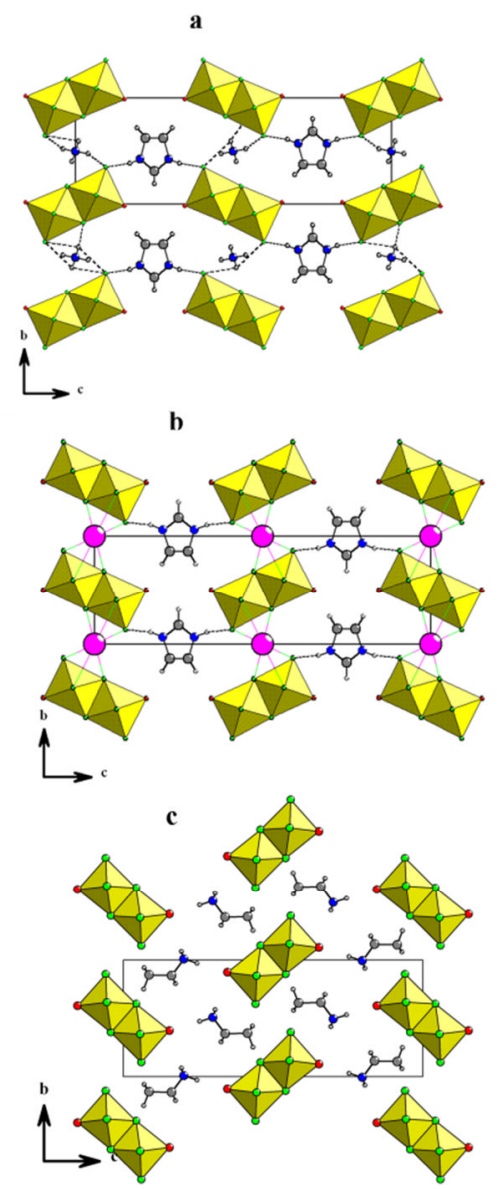

Fig.11 Structure of VOF-5 (a),VOF-6 (b) and VOF-7 (c) viewed along the $a$ axis

previously been reported for divalent metal chlorides bridged by bipy ${ }^{15-17}$ and trans-connected single chains have also been seen in vanadium and magnesium fluorides bridged by bipy, $, \underline{6}, \underline{18}$ but there 10 are no previous reports on "zigzag" edge-sharing chains in metalhalide/organic coordination polymers.

VOF-4 was synthesised using the same procedure as VOF-2, the only difference being the reaction temperature $\left(140^{\circ} \mathrm{C}\right.$ for VOF-4 and $170^{\circ} \mathrm{C}$ for $\left.\mathbf{V O F}-2\right)$. It is interesting to see how the reaction 15 temperature affects the resulting materials and also the protonation of the organic amine involved within the synthesis.

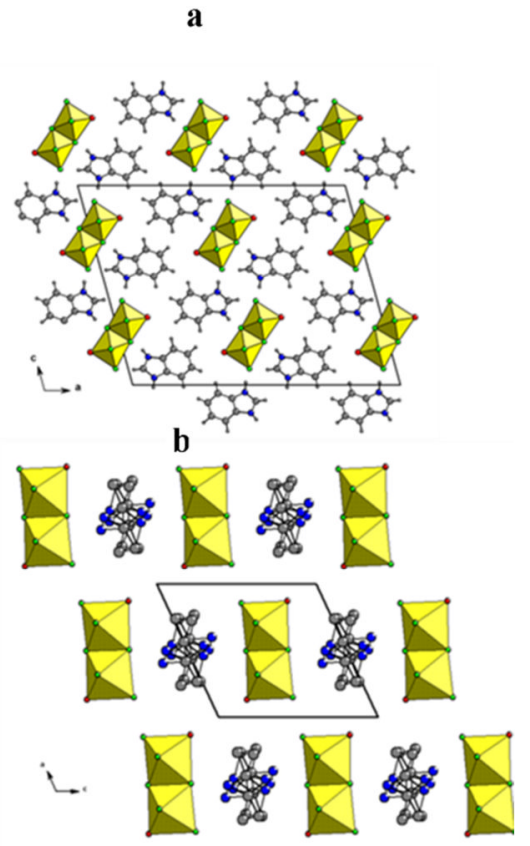

Fig.12 Structures of VOF-8 (a) and VOF-9 (b) viewed along the $b$ axis

High temperature reaction conditions led to more condensation of 20 the inorganic framework to form 2-D anionic inorganic sheets templated by protonated pyrazinium cations, whereas lower reaction temperatures did not favour either increased condensation of the inorganic framework or the protonation of pyrazine, and hence a 2-D coordination polymer was formed.

25

VOF-5, VOF-6, VOF-7, VOF-8, VOF-9, VOF-10, VOF-11 and VOF-12 all display the same inorganic ladder-type chain previously reported for $\mathrm{CsVOF}_{3}, \alpha-\mathrm{RbVOF}_{3}$ and $\left[\mathrm{H}_{2} b p e\right]_{1 / 2} \mathrm{VOF}_{3}{ }^{19}$ This ladder (Fig.2) is constructed from the 30 edge-sharing dimer described earlier (see Fig.1(a)), with each dimer sharing two further $\mathrm{F}$ atoms with adjacent dimers, leaving one $\mathrm{F}$ and one $\mathrm{O}$ atom terminal.

All the ladder type materials contain one single vanadium site in the asymmetric unit, with bond valence sum calculations 35 indicating a 4+ oxidation state in each case.

Interestingly, this type of vanadium octahedral connectivity can be achieved using organic, inorganic or mixed organic-inorganic templates, and is produced using either solvothermal or ionothermal synthesis.

${ }_{40}$ While the ladder-like motif always displays essentially the same structural features (i.e. distribution of bond lengths and the orientation of the vanadyl bond), the different templates involved in the synthesis dictate different overall crystal-packing characteristics. In fact, it is not only the template that affects the 45 overall structural features: a subtle change in the reaction conditions can give rise to different polymorphs of the same composition. For example, prior to our synthesis of VOF-10 a different modification (now designated $\alpha-\mathrm{RbVOF}_{3}$ ) had been reported $^{19}$ and was synthesised using a solution of $1: 1$ ${ }_{50} \mathrm{H}_{2} \mathrm{O}$ /ethylene glycol. Changing the mixed solvent system to $3: 1$ $\mathrm{H}_{2} \mathrm{O} / \mathrm{DMSO}$ led to the second polymorph (VOF-10, or $\beta$ $\mathrm{RbVOF}_{3}$ ) with a different ladder packing scheme. Also VOF-11 


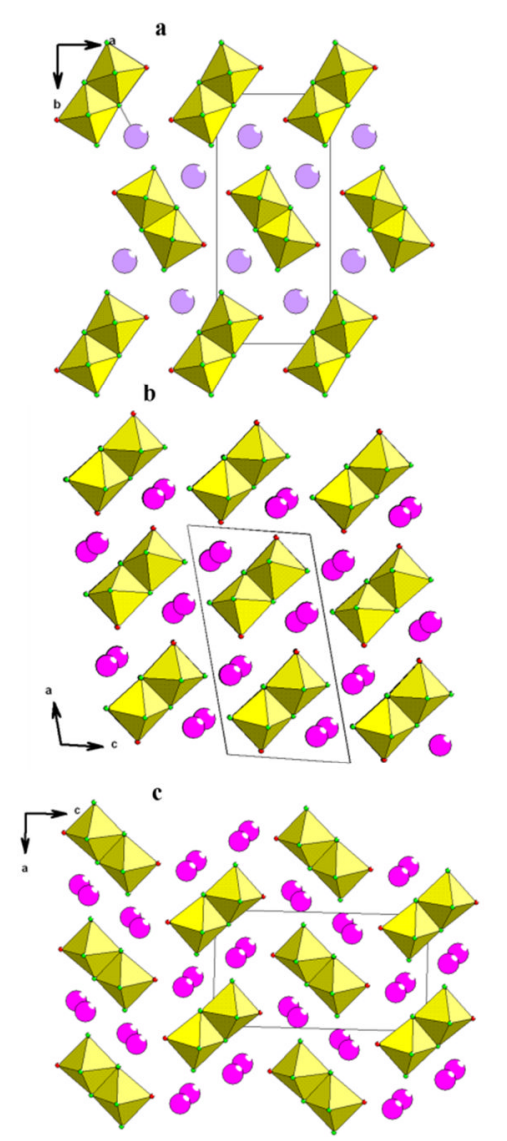

Fig.13 Structures of VOF-10 (a) viewed along the $c$ axis, VOF-11 (b) and VOF-12 (c) viewed along the $b$ axis

and VOF-12, polymorphs of $\mathrm{KVOF}_{3}$, can both be synthesised by 5 varying the ratio of the mixed solvent system and the temperature.

The crystal packing schemes for VOF-5, VOF-6, VOF-7, VOF8, VOF-9, VOF-10, VOF-11 and VOF-12 are shown in Fig 11, 12 and 13.

${ }_{10}$ It is worth mentioning, here, that the layer structure VOF-1 and the ladder VOF-8 have been prepared using the same template benzimidazole; using $1 \mathrm{mmol}$ led to VOF-1 as a pure phase, slightly increasing this amount to $1.5 \mathrm{mmol}$ led to a sample containing mixed phases of VOF-1 and VOF-8. The layered 15 structure VOF-3 also coexists with the ladder type structure VOF-5, and several attempts to prepare them phase-pure were not successful (See supplementary for more details on the synthesis conditions and also PXRDs for the samples)

The crystal structure of VOF-13 shows an interesting variation of 20 the 'standard' $\left[\mathrm{VOF}_{3}\right]_{\mathrm{n}}{ }^{\mathrm{n}-}$ ladder-type described above. In the standard ladder, the edge-sharing dimer can be considered as the rung of the ladder, with each octahedral unit of the dimer further sharing one $\mathrm{F}$ atom with adjacent octahedra to form the rails (Fig.2). In contrast, VOF-13 can be regarded as an "alternating ${ }_{25}$ ladder-type structure" where the edge-sharing dimer is not the rung of the ladder but instead forms part of the rails; the rung is the tetrameric unit formed when the dimers share two further $\mathrm{F}$ atoms, and these tetrameric units are linked to each other by sharing two more F atoms (Fig.14). Fig.15 shows the "buckled" 30 nature of the "alternating" ladder compared to the "standard"ladder.

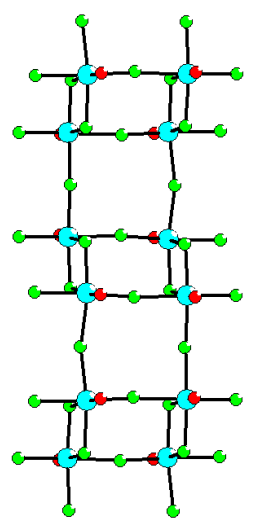

Fig.14 Topology of the $\left[\mathrm{VOF}_{3}\right]_{\mathrm{n}}{ }^{\mathrm{n}-}$ "alternating ladder" chain

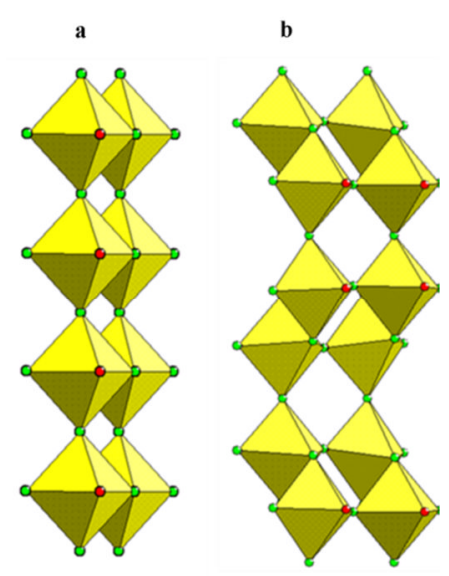

Fig.15 A view showing the standard ladder (a) and the alternating ladder (b)

It can also be seen that both types of ladders, the 'standard' and the 'alternating' one may be regarded as constituent motifs of the 40 layers found in VOF-1 and VOF-2 (See Fig.S11 in the supplementary) where the "standard ladder" can be seen in the vertical direction, while the "alternating ladder" appears in the horizontal direction.

In VOF-13, the ladders are linked together by protonated 45 ethylenediammonium cations as illustrated in Fig.16.

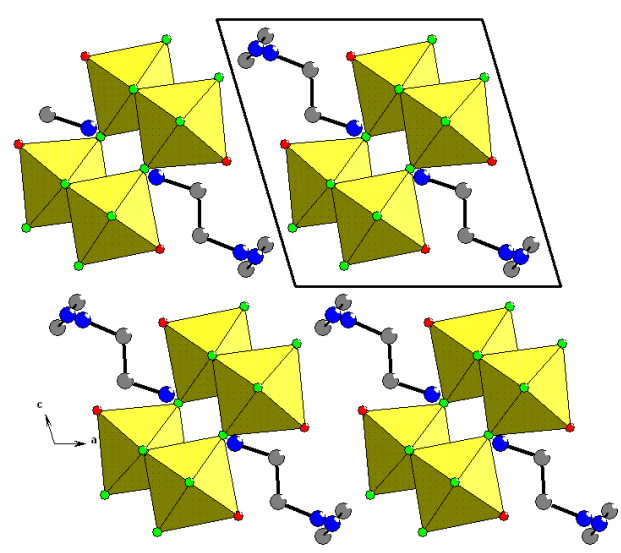

Fig.16 VOF-13 viewed along the $b$ axis 


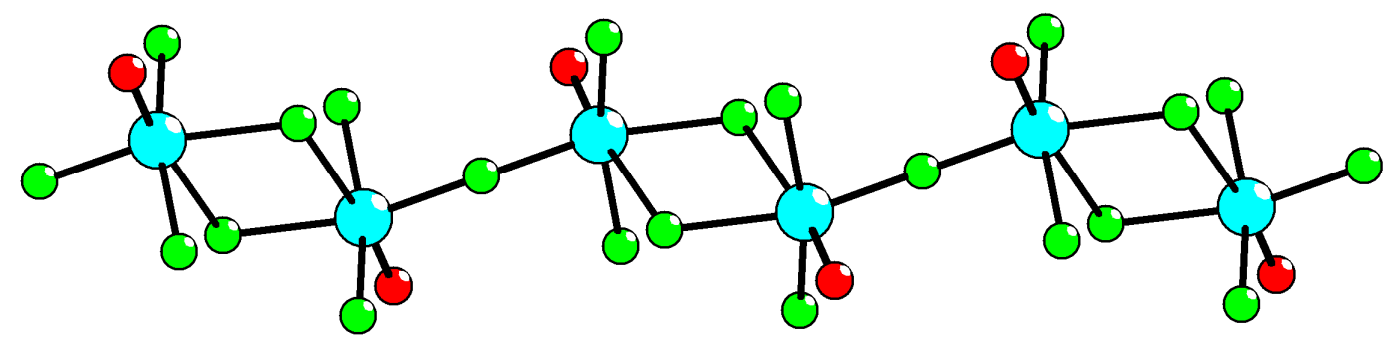

Fig.17 Unique chain type $\left[\mathrm{V}_{2} \mathrm{O}_{2} \mathrm{~F}_{7}\right]_{\mathrm{n}}{ }^{2 \mathrm{n}-}$ motif found in VOF-14
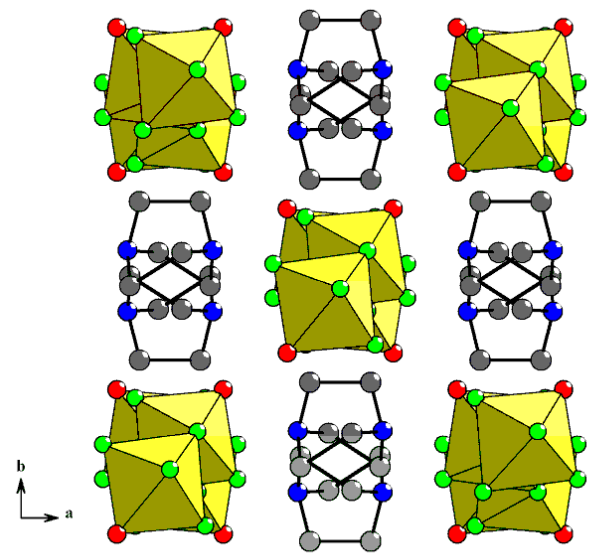

Fig.18 A view of VOF-14 along the $c$ axis

VOF-14 has a novel chain type structure. Again, this chain, as illustrated in Fig.17, is formed from the edge-sharing dimers described earlier, with each dimeric unit sharing only one further

${ }_{10} \mathrm{~F}$ atom with neighbouring units, leaving two $\mathrm{F}$ atoms and one $\mathrm{O}$ atom terminal. The chains are connected through protonated DABCO cations as shown in Fig.18. It is worth noting that according to the bond valence sum calculations, $\left(\sum \mathrm{V} 1=4.77\right)$ and also looking at the formula (with only one $\mathrm{H}_{2} \mathrm{DABCO}$ ), 15 vanadium occurs in a mixed $+4 /+5$ oxidation states.

\section{Magnetic Susceptibility}

As shown in Fig.19, magnetic susceptibility data for VOF-13 show evidence for low-dimensional antiferromagnetic order, with a broad maximum in the plot of $\chi$ versus $\mathrm{T}$ near $50 \mathrm{~K}$. (see the 20 inset in Fig.19) Above $150 \mathrm{~K}$ the data fit well to a Curie-Weiss law, with a Weiss constant $\theta=-90 \mathrm{~K}$ indicating relatively strong antiferromagnetic interactions. The experimental effective magnetic moment $\mu_{\text {eff }}=2.29 \mu_{\mathrm{B}}$; in good agreement with the ideal value for two isolated spin $1 / 2$ species (i.e two V(IV) per 25 formula unit), $\mu_{\text {ideal }}=2.45 \mu_{\mathrm{B}}$.

Various simple models were used to attempt to fit the $\chi(\mathrm{T})$ data, including Bleaney-Bowers dimer, 1D Ising or Heisenberg chains and spin ladder models. The best fit was produced from a 1-D S =

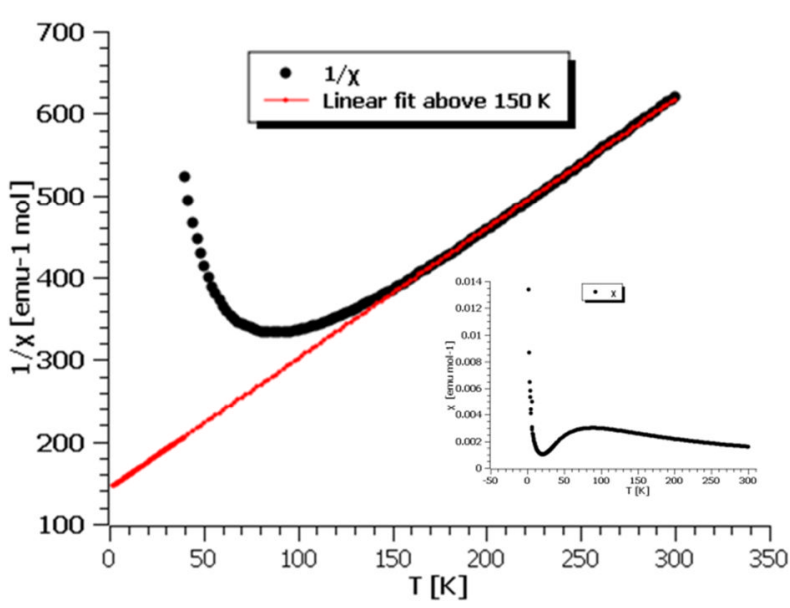

30 Fig.19 Plot of $1 / \chi$ versus $\mathrm{T}$ and the Curie-Weiss fit above $150 \mathrm{~K}$ for VOF-13; the inset shows the plot of $\chi$ versus $\mathrm{T}$

$1 / 2$ Ising chain model (See supplementary material), rather than the Heisenberg chain (in contrast to the ladder compound $\left.\mathrm{CsVOF}_{3}\right) . \underline{19}$

\section{${ }_{35}$ Conclusions}

The reaction of $\mathrm{VOF}_{3}$ or $\mathrm{V}_{2} \mathrm{O}_{5}, \mathrm{HF}$ and an appropriate organic, inorganic or mixed templating source in a suitable solvent (IL or a solution of $\mathrm{H}_{2} \mathrm{O} / \mathrm{DMSO}$ or $\mathrm{H}_{2} \mathrm{O}$ /ethylene glycol) yielded 14 novel materials, that considerably expand and enrich the list of 40 existing VOFs. Both ionothemal and solvothermal systems are shown to be fruitful media to target these types of materials. These results emphasise once more the propensity of ionothermal synthesis to produce more extended structures, with the isolation of four novel materials displaying 2-D connectivities, although 45 ladder type structures and 1-D chains are still accessible ionothermally. In ionothermal synthesis using a hydrophobic IL, EMIM $\mathrm{Tf}_{2} \mathrm{~N}$, the nature and the amount of the templating source involved in the synthesis has a great effect on the dimensionality of the final material. The reaction temperature can also affect the 50 degree of protonation of template. High reaction temperature leads to the protonation of pyrazine and the formation of a 2-D inorganic layer with the pyrazinium cations acting as a template and charge balancing agent (VOF-2), while lower temperature yielded a neutral layered coordination polymer with pyrazine 55 acting as a coordinating ligand (VOF-4). Solvothermal synthesis yielded three different phases displaying ladder like topologies and it is found that a subtle change in the reaction conditions affects the conformation of the ladders and their packing within the unit cell (VOF-10, VOF-11, VOF-12). While this exploration 60 yielded several interesting materials, it is apparent that there is still much more scope to develop further the chemistry of VOFs, 
leading to other new VOF framework types and potentially novel physical or chemical properties.

\section{Acknowledgements}

We thank Dr Phoebe K. Allan and Dr Catherine Renouf for 5 assistance in collecting diffraction data for VOF-1 and Mr Lewis J. Downie for assistance in collecting the magnetic data. We thank the EPSRC for funding under grant numbers EP/F021925 and EP/K005499/1. FHA also acknowledges support from the EPSRC Doctoral Prize Fellowships scheme.

\section{Notes and references}

${ }^{a}$ EaStChem, School of Chemistry, University of St Andrews, St Andrews, Fife, UK KY16 9ST.; E-mail: xxxx@aaa.bbb.ccc

$\dagger \quad$ Electronic Supplementary Information (ESI) available: See DOI: 10.1039/b000000x/

${ }_{15}$ Colour scheme used in all pictures: Vanadium (light blue), Fluorine (green), Oxygen (red), Nitrogen (dark blue), Carbon (dark grey), Hydrogen (light grey), Potassium (pink) and Rubidium (purple).

\section{$\ddagger$}

20 (1) Song, J.; Xu, M.; Wang, L.; Goodenough, J. B. Chem. Commun. 2013, 49, 5280.

(2) Tsirlin, A. A.; Rosner, H. Phys. Rev. B 2009, 79, 214417.

(3) Eichelbaum, M.; Hävecker, M.; Heine, C.; Karpov, A.; Dobner, C.-K.; Rosowski, F.; Trunschke, A.; Schlögl, R. Angew. ${ }_{25}$ Chem. Int. Ed. 2012, 51, 6246.

(4) Adil, K.; Leblanc, M.; Maisonneuve, V.; Lightfoot, P. Dalton Trans. 2010, 39, 5983.

(5) Mahenthirarajah, T.; Li, Y.; Lightfoot, P. Inorg. Chem. 2008, 47, 9097.

30 (6) Aldous, D. W.; Stephens, N. F.; Lightfoot, P. Inorg. Chem. 2007, 46, 3996.

(7) Aldous, D. W.; Stephens, N. F.; Lightfoot, P. Dalton Trans. 2007, 2271.

(8) Aldous, D. W.; Stephens, N. F.; Lightfoot, P. Dalton Trans. $352007,4207$.

(9) Morris, R. E. Chem. Commun. 2009, 2990.

(10) Himeur, F.; Allan, P. K.; Teat, S. J.; Goff, R. J.; Morris, R. E.; Lightfoot, P. Dalton Trans. 2010, 39, 6018.

(11) Aidoudi, F. H.; Aldous, D. W.; Goff, R. J.; 40 SlawinAlexandra, M. Z.; Attfield, J. P.; Morris, R. E.; Lightfoot, P. Nat. Chem. 2011, 3,801.

(12) Clark, L.; Orain, J. C.; Bert, F.; De Vries, M. A.; Aidoudi, F. H.; Morris, R. E.; Lightfoot, P.; Lord, J. S.; Telling, M. T. F.; Bonville, P.; Attfield, J. P.; Mendels, P.; Harrison, A. Phys. Rev. ${ }_{45}$ Lett. 2013, 110, 207208.

(13) Bonhote, P.; Dias, A.-P.; Papageorgiou, N.; Kalyanasundaram, K.; Gratzel, M. Inorg. Chem. 1996, 35, 1168.

(14) Owens, G. S.; Abu-Omar, M. M. J. Mol. Catal. A: Chem. 2002, 187, 215.

50 (15) Lawandy, M. A.; Huang, X.; Wang, R.-J.; Li, J.; Lu, J. Y.; Yuen, T.; Lin, C. L. Inorg. Chem. 1999, 38, 5410.

(16) Hu, C.; Englert, U. Angew. Chem. Int. Ed. 2005, 44, 2281.
(17) Chippindale, A. M.; Cowley, A. R.; Peacock, K. J. Acta Crystallog. Sect. C 2000, 56, 651.

55 (18) Darriet, J.; Massa, W.; Pebler, J.; Stief, R. Solid State Sci. 2002, 4, 1499.

(19) Aldous, D. W.; Goff, R. J.; Attfield, J. P.; Lightfoot, P. Inorg. Chem. 2007, 46, 1277. 